\title{
Association between lung compliance phenotypes and mortality in COVID-19 patients with acute respiratory distress syndrome
}

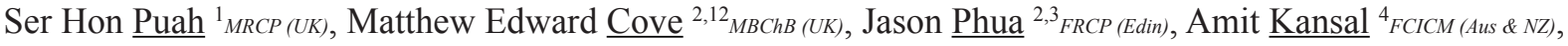

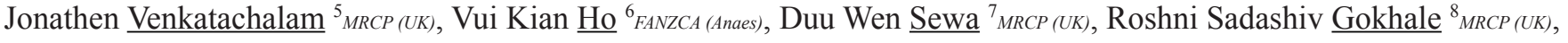

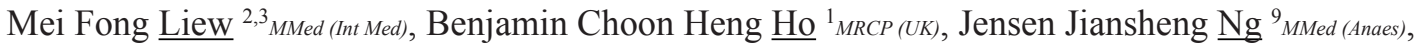
John A A bisheganaden ${ }^{1,10_{F R C P}(\text { Edin })}$, Yee Sin Leo ${ }^{10,11,12,13,14_{\text {FRCP }} \text {, Barnaby Edward Young }}{ }^{10,11,12}{ }_{\text {DLSHTM }}$, David Chien Lye ${ }^{10,11,12,13}$ FRCP (UK), Tsin Wen $\underline{\text { Yeo }}^{10,11,12}$ PhD, on behalf of Singapore 2019 Novel Coronavirus Outbreak Research Team

\begin{abstract}
Introduction: Acute respiratory distress syndrome (ARDS) in COVID-19 is associated with a high mortality rate, though outcomes of the different lung compliance phenotypes are unclear. We aimed to measure lung compliance and examine other factors associated with mortality in COVID-19 patients with ARDS.

Methods: Adult patients with COVID-19 ARDS who required invasive mechanical ventilation at 8 hospitals in Singapore were prospectively enrolled. Factors associated with both mortality and differences between high $\left(<40 \mathrm{~mL} / \mathrm{cm} \mathrm{H}_{2} \mathrm{O}\right)$ and low $\left(<40 \mathrm{~mL} / \mathrm{cm} \mathrm{H}_{2} \mathrm{O}\right)$ compliance were analysed.

Results: A total of 102 patients with COVID-19 who required invasive mechanical ventilation were analysed; $15(14.7 \%)$ did not survive. Non-survivors were older (median 70 years, interquartile range [IQR] $67-75$ versus median 61 years, IQR 52-66; $P<0.01$ ), and required a longer duration of ventilation ( 26 days, IQR $12-27$ vs 8 days, IQR $5-15 ; P<0.01)$ and intensive care unit support (26 days, IQR $11-30$ vs 11.5 days, IQR $7-17.3 ; P=0.01$ ), with a higher incidence of acute kidney injury (15 patients $[100 \%]$ vs 40 patients $[46 \%] ; P<0.01$ ). There were 67 patients who had lung compliance data; 24 (35.8\%) were classified as having high compliance and $43(64.2 \%)$ as having low compliance. Mortality was higher in patients with high compliance $(33.3 \%$ vs $11.6 \% ; P=0.03)$, and was associated with a drop in compliance at day $7\left(-9.3 \mathrm{~mL} / \mathrm{cm} \mathrm{H}_{2} \mathrm{O}\right.$ (IQR -4.5 to -15.4$) \mathrm{vs} 0.2 \mathrm{~mL} / \mathrm{cm} \mathrm{H}_{2} \mathrm{O}(4.7$ to -5.2$)$ $P=0.04)$.
\end{abstract}

Conclusion: COVID-19 ARDS patients with higher compliance on the day of intubation and a longitudinal decrease over time had a higher risk of death.

Ann Acad Med Singap 2021;50:686-94

Keywords: ARDS, COVID-19-associated respiratory failure, high-flow nasal cannula therapy, HFNC, post-intubation, ventilation strategies

\footnotetext{
${ }^{1}$ Department of Respiratory and Critical Care Medicine, Tan Tock Seng Hospital, Singapore

${ }^{2}$ Division of Respiratory and Critical Care Medicine, Department of Medicine, National University Hospital, Singapore

${ }^{3}$ Fast and Chronic Programmes, Alexandra Hospital, Singapore

${ }^{4}$ Department of Intensive Care Medicine, Ng Teng Fong General Hospital, Singapore

${ }^{5}$ Department of Respiratory and Critical Care Medicine, Khoo Teck Puat Hospital, Singapore

${ }^{6}$ Department of Intensive Care Medicine, Sengkang General Hospital, Singapore

${ }^{7}$ Department of Respiratory and Critical Care Medicine, Singapore General Hospital, Singapore

${ }^{8}$ Department of General Medicine, Changi General Hospital, Singapore

${ }^{9}$ Department of Anaesthesiology, Intensive Care and Pain Medicine, Tan Tock Seng Hospital, Singapore

${ }^{10}$ Lee Kong Chian School of Medicine, Nanyang Technological University, Singapore

${ }^{11}$ Department of Infectious Diseases, Tan Tock Seng Hospital, Singapore

${ }^{12}$ National Centre for Infectious Diseases, Singapore

${ }^{13}$ Yong Loo Lin School of Medicine, National University of Singapore, Singapore

${ }^{14}$ Saw Swee Hock School of Public Health, National University of Singapore, Singapore

Correspondence: Prof Tsin Wen Yeo, Lee Kong Chian School of Medicine, Novena Campus, Clinical Sciences Building, 11 Mandalay Road, Level 18, Singapore 308232 .

Email: yeotsinwen@ntu.edu.sg
} 


\section{CLINICAL IMPACT}

\section{What is New}

- A portion of COVID-19 ARDS patients can present with high lung compliance following endotracheal intubation.

- This study shows that mechanically ventilated COVID-19 patients who had high initial lung compliance that subsequently decreased during their intensive care unit stay had an increased risk of mortality.

\section{Clinical Implications}

- Patients with COVID-19 ARDS may initially have high compliance, which can deteriorate over time.

- Lung ventilation strategies have to be adapted and monitored to manage COVID-19 patients with ARDS who show high initial lung compliance upon intubation.

\section{INTRODUCTION}

In December 2019, the city of Wuhan in China was the centre of a pneumonia outbreak caused by an unknown agent. ${ }^{1-3}$ It was subsequently discovered to be a novel betacoronavirus, the severe acute respiratory syndrome coronavirus 2 (SARS-CoV-2), ${ }^{4}$ while the resulting clinical disease has been known as coronavirus disease 2019 (COVID-19). Since then, SARS-COV-2 has spread around the world, resulting in over 219 million cases of COVID-19 and more than 4.5 million deaths as of 20 September 2021.

It is estimated that $15-30 \%$ of hospitalised COVID-19 patients develop critical illness and require either non-invasive or invasive respiratory support. ${ }^{1-3,5}$ The need for invasive ventilation due to acute respiratory distress syndrome (ARDS) in COVID-19 patients is associated with high mortality, with rates of up to $48-65 \%$ in reports from Wuhan. ${ }^{1-3,6}$ High rates were similarly observed in other countries. ${ }^{5,7-9}$ In comparison, reported mortality rates for non-COVID-19 ARDS range from $35-46 \% .{ }^{10}$ One possible explanation proposed for the higher mortality includes atypical pulmonary physiology observed in ARDS patients with COVID-19. ${ }^{11}$ It has been reported that $70 \%$ of intubated Italian patients had preserved lung compliance, despite severe hypoxaemia. ${ }^{11}$ This has been described as a high compliance phenotypeassociated specifically with COVID-19-compared to the more familiar ARDS phenotype where compliance is low. ${ }^{11,12}$
Recognition of different ARDS phenotypes may have clinical relevance, since they may respond differently to the same ventilator settings, leading to different outcomes. ${ }^{12,13}$ Heterogeneity within non-COVID-19 ARDS patients has previously been described-latent class analysis identified 2 distinct phenotypes based on inflammatory profiles in well-defined clinical cohorts. ${ }^{14}$ However, lung compliance data were not assessed.

The differences between COVID-19 patients with high and low compliance phenotypes have not been well described within the literature, and the impact of ventilation strategy on the outcomes among the 2 groups has also not been documented. Such data is necessary for informed phenotype-specific ventilatory management. ${ }^{12}$ In this prospective case series of intubated COVID-19 patients in Singapore, we aimed to investigate factors that affect mortality in patients with COVID-19 ARDS and the implication of lung compliance phenotypes on mortality.

\section{METHODS}

\section{Study population}

All adult patients with COVID-19 ARDS who required invasive mechanical ventilation were enrolled from 23 January to 11 May 2020, and followed up prospectively. COVID-19 diagnosis was confirmed by SARS-CoV-2 real-time polymerase chain reaction as previously described. ${ }^{15}$ Patients were isolated and managed in the intensive care units (ICUs) of 8 public hospitals with negative pressure facilities. Collection of deidentified clinical data and waiver of written informed consent were approved by the Ministry of Health, Singapore under the Infectious Disease Act.

\section{Data collection}

We collected epidemiological data (age, sex, ethnicity, clinical symptoms and comorbidities), laboratory results on hospital admission and ICU transfer (haemoglobin, leukocyte, neutrophil, lymphocyte and platelet counts; lactate dehydrogenase, C-reactive protein, creatinine and arterial blood gas levels), fraction of inspired oxygen $\left(\mathrm{FiO}_{2}\right)$ concentration, radiological findings, ventilator mechanics (modes of ventilation, plateau pressures, positive end-expiratory pressures [PEEPs] and tidal volumes) and supportive therapy (oxygen therapy, dialysis and vasopressors) for all patients admitted to ICU. Data collection was completed on 18 May 2020 and outcomes were collated on 1 June 2020. Two researchers individually reviewed the data forms, and inconsistent or missing data were clarified with site investigators. If inconsistencies were not resolved, the patient's data were rejected and not analysed. 


\section{Definitions}

We defined the date of onset of disease as the first day of symptoms reported by the patient. We defined ARDS and their severity according to the Berlin criteria, ${ }^{16}$ and acute kidney injury in accordance with the Kidney Disease: Improving Global Outcomes (KDIGO) guidelines. ${ }^{17}$

Patients were managed using a lung protective strategy, as defined by the Acute Respiratory Distress Syndrome Clinical Network (ARDSnet) guidelines (i.e. targeting plateau pressures below $30 \mathrm{~cm} \mathrm{H}_{2} \mathrm{O}$ by keeping tidal volume settings between 4 and $8 \mathrm{~mL} / \mathrm{kg}$ of predicted body weight). Driving pressure was defined as the difference between plateau pressure and PEEP. Plateau pressures were acquired by performing an endinspiratory breath hold manoeuvre, with the patient either on neuromuscular blockers or deep sedation to prevent spontaneous respiration. This was done within the first 12 hours of ventilation and was repeated based on the discretion of the treating physician.

High compliance phenotype was defined as a static compliance of $<40 \mathrm{~mL} / \mathrm{cm} \mathrm{H}_{2} \mathrm{O}$ while low compliance was defined as a static compliance of $<40 \mathrm{~mL} / \mathrm{cm} \mathrm{H}_{2} \mathrm{O}$ as previously described. ${ }^{13,18}$ In this study, static compliance was calculated using exhaled tidal volumes divided by the driving pressure.

\section{Statistical analysis}

The group characteristics, respiratory physiological parameters, and outcomes in all patients were analysed. The difference in outcomes between the high and low compliance phenotypes were evaluated. Continuous variables were expressed as mean (standard deviation [SD]) or median (interquartile range [IQR]) depending on distribution, and categorical variables were expressed as frequency and percentage. We compared differences for continuous variables using two-sample t-test or Wilcoxon rank-sum test depending on the distribution, and chi-square test or Fisher's exact test for categorical variables. Logistic regression was used to adjust for factors associated with death and the high and low compliance phenotype. We used an agnostic approach to determine the covariates included in the model, performing forward variable selection with the likelihood ratio test to add covariates one at a time. At each variable selection step, the most significant covariate that was not in the current model was added if its $P$ value was $<0.05$. No further covariates were added if the remaining covariates had $P$ values $>0.05$. Tests were two-sided with significance level set at $<0.05$. Analyses were performed using MedCalc statistical software version 19.1.7 (MedCalc Software Ltd, Ostend, Belgium) and STATA version 13.1 (StataCorp, College Station, US).

\section{RESULTS}

\section{Baseline characteristics}

There were 102 patients with confirmed COVID-19 who required invasive ventilation in the ICU between 23 January and 11 May 2020. The median age was 62 years (IQR 54-68), 75 (73.5\%) were male and the median body mass index was 26 (IQR 23.3-30.5). There were $64(62.8 \%)$ patients with hypertension, 52 (51\%) with hyperlipidaemia, 38 (37.3\%) with diabetes mellitus and $17(16.7 \%)$ with ischaemic heart disease. A total of $15(14.7 \%)$ patients had a fatal outcome. There was no difference in baseline demographics, comorbidities and baseline lab investigations between survivors and non-survivors (Table 1).

Table 1. Patient demographics, comorbidities and lab investigations

\begin{tabular}{|c|c|c|c|c|}
\hline & $\begin{array}{l}\text { Total patients } \\
\quad(\mathrm{N}=102)\end{array}$ & $\begin{array}{l}\text { Survivors } \\
\quad(\mathrm{n}=87)\end{array}$ & $\begin{array}{l}\text { Non-survivors } \\
\quad(n=15)\end{array}$ & $P$ value \\
\hline \multicolumn{5}{|l|}{ Demographics } \\
\hline Age, median (IQR), years & $62(54-68)$ & $61(53-66)$ & $70(64-75)$ & $<0.01$ \\
\hline Male, no. (\%) & $75(73.5)$ & $62(71.3)$ & $13(86.7)$ & 0.34 \\
\hline BMI, median (IQR), $\mathrm{kg} / \mathrm{m}^{2}$ & $26(23.2-30.6)$ & $26(23.4-30.7)$ & $26.3(22.7-28)$ & 0.29 \\
\hline \multicolumn{5}{|l|}{ Race, no. (\%) } \\
\hline Chinese & $62(60.8)$ & $54(62.1)$ & $8(53.3)$ & 0.52 \\
\hline Malay & $17(16.7)$ & $16(18.4)$ & $1(6.7)$ & 0.46 \\
\hline Indian & $10(9.8)$ & $7(8.0)$ & $3(20)$ & 0.16 \\
\hline Others & $13(12.7)$ & $10(11.5)$ & $3(20)$ & 0.40 \\
\hline
\end{tabular}


Table 1. Patient demographics, comorbidities and lab investigations (Cont'd)

\begin{tabular}{|c|c|c|c|c|}
\hline & $\begin{array}{l}\text { Total patients } \\
\qquad(\mathrm{N}=102)\end{array}$ & $\begin{array}{l}\text { Survivors } \\
(\mathrm{n}=87)\end{array}$ & $\begin{array}{c}\text { Non-survivors } \\
(n=15)\end{array}$ & $P$ value \\
\hline \multicolumn{5}{|l|}{ Comorbidities, no. (\%) } \\
\hline Hypertension & $64(62.7)$ & $55(63.2)$ & $9(60)$ & 0.81 \\
\hline Diabetes mellitus & $38(37.3)$ & $32(36.8)$ & $6(40)$ & 0.81 \\
\hline Hyperlipidaemia & $52(51)$ & $45(51.7)$ & $7(46.7)$ & 0.72 \\
\hline Ischaemic heart disease & $17(16.7)$ & $12(13.8)$ & $5(33.3)$ & 0.13 \\
\hline Cerebrovascular accident & $5(4.9)$ & $5(5.7)$ & 0 & 1.00 \\
\hline Congestive cardiac failure & $4(3.9)$ & $4(4.5)$ & 0 & 1.00 \\
\hline Cancer & $8(7.8)$ & $6(6.9)$ & $2(13.3)$ & 0.33 \\
\hline Asthma & $4(3.9)$ & $3(3.4)$ & $1(6.7)$ & 0.48 \\
\hline \multicolumn{5}{|l|}{ Severity scores, median (IQR) } \\
\hline APACHE II & $14(10-22)$ & $14(10-22)$ & $13.5(10.8-20.3)$ & 0.93 \\
\hline SOFA & $4(2-7)$ & $4(2-8)$ & $3(2.8-4.3)$ & 0.01 \\
\hline \multicolumn{5}{|l|}{ Lab investigations, median (IQR) } \\
\hline White cells, $\times 10^{9} / \mathrm{L}$ & $7.8(5.6-10.2)$ & $8.1(6.1-10.1)$ & $5.7(3.4-12.7)$ & 0.47 \\
\hline Neutrophils, x $10^{9} / \mathrm{L}$ & $6.2(3.9-8.5)$ & $6.6(4.3-8.5)$ & $4.2(2.7-10.2)$ & 0.09 \\
\hline Lymphocytes, x $10^{9} / \mathrm{L}$ & $0.78(0.57-1.14)$ & $0.79(0.59-1.2)$ & $0.61(0.5-0.9)$ & 0.07 \\
\hline Haemoglobin, mg/dL & $13.3(12.1-14.2)$ & $13.1(12-14.1)$ & $13.5(12.6-14.6)$ & 0.34 \\
\hline Procalcitonin, $\mu \mathrm{g} / \mathrm{L}$ & $0.31(0.13-0.69)$ & $0.31(0.13-0.71)$ & $0.29(0.11-0.44)$ & 0.47 \\
\hline Creatinine, $\mu \mathrm{mol} / \mathrm{L}$ & $82(64-100)$ & $79.5(62.5-100)$ & $91(72-107)$ & 0.34 \\
\hline Lactate dehydrogenase, U/L & 675 (449-919) & $658(433-891)$ & $721(517-1161)$ & 0.22 \\
\hline Albumin, $\mathrm{g} / \mathrm{L}$ & $33(30-36)$ & $33(30-36)$ & $33(30-35)$ & 0.34 \\
\hline Alanine transaminase, $\mathrm{U} / \mathrm{L}$ & $39(24-60)$ & $40(24-83)$ & $36(25-44)$ & 0.41 \\
\hline Aspartate aminotransferase, U/L & $51(38-74)$ & $50.5(37.5-81.3)$ & $55.5(34-67.5)$ & 0.50 \\
\hline Alkaline phosphatase, $\mathrm{U} / \mathrm{L}$ & $84(59-108)$ & $85(61-118)$ & $61(55-90)$ & 0.12 \\
\hline \multicolumn{5}{|l|}{ Outcomes, no. (\%) } \\
\hline Shock & $59(57.8)$ & $52(59.8)$ & $7(46.7)$ & 0.34 \\
\hline Cardiac event ${ }^{\mathrm{a}}$ & $23(22.5)$ & $17(19.5)$ & $6(40)$ & 0.08 \\
\hline Ventilator associated pneumonia & $36(35.3)$ & $27(31)$ & $9(60)$ & 0.03 \\
\hline Pneumothorax & $5(4.9)$ & $5(5.7)$ & 0 & 1.00 \\
\hline Extracorporeal membrane oxygenation & $5(4.9)$ & $3(3.4)$ & $2(13.3)$ & 0.24 \\
\hline Acute kidney injury & $55(53.9)$ & $40(46.0)$ & $15(100)$ & $<0.01$ \\
\hline Dialysis & $30(29.4)$ & $16(20.3)$ & $14(93.3)$ & $<0.01$ \\
\hline
\end{tabular}

APACHE II: Acute Physiology and Chronic Health Evaluation II; BMI: body mass index; IQR: interquartile range; SOFA: sequential organ failure score

a Non-ST-elevated myocardial infarction, type 2 myocardial infarction or atrial fibrillation 
Table 2. Oxygen requirements prior to intubation, patients' severity of ARDS, lung ventilation mechanics and mortality outcomes of patients with compliance data

\begin{tabular}{|c|c|c|c|c|}
\hline & $\begin{array}{c}\text { Total } \\
(\mathrm{N}=67)\end{array}$ & $\begin{array}{l}\text { High compliance } \\
\qquad(n=24)\end{array}$ & $\begin{array}{c}\text { Low compliance } \\
\qquad(n=43)\end{array}$ & $P$ value \\
\hline \multicolumn{5}{|l|}{ Oxygen delivery prior to intubation } \\
\hline Nasal cannula, no. $(\%)$ & $10(15.2)$ & $5(20.8)$ & $5(11.6)$ & 0.48 \\
\hline Venturi mask, no. (\%) & $19(28.8)$ & $8(33.3)$ & $11(25.5)$ & 0.54 \\
\hline Non-rebreather mask, no. (\%) & $20(30.3)$ & $6(25)$ & $14(32.5)$ & 0.48 \\
\hline High-flow nasal cannula, no. (\%) & $22(32.8)$ & $6(25)$ & $16(37.2)$ & 0.31 \\
\hline $\mathrm{PaO}_{2} / \mathrm{FiO}_{2}$ prior to intubation ${ }^{\mathrm{a}}$ & $128(85-170)$ & $145(112-183)$ & $112(76-161)$ & 0.05 \\
\hline $\mathrm{PaO}_{2} / \mathrm{FiO}_{2}$ after intubation ${ }^{\mathrm{a}}$ & $175(138-223)$ & $166(137-226)$ & $176(138-220)$ & 0.53 \\
\hline \multicolumn{5}{|l|}{ Patients' severity of ARDS, no. (\%) } \\
\hline Mild ARDS & $23(34.3)$ & $10(41.7)$ & $13(30.2)$ & 0.35 \\
\hline Severe ARDS & $8(11.9)$ & $1(4.2)$ & $7(16.3)$ & 0.24 \\
\hline \multicolumn{5}{|l|}{ Lung ventilation mechanics } \\
\hline Positive end-expiratory pressure, $\mathrm{cm} \mathrm{H}_{2} \mathrm{O}^{\mathrm{a}}$ & $12(10-14)$ & $12(10-13.5)$ & $10(10-14)$ & 0.94 \\
\hline Tidal volume, $\mathrm{mL} / \mathrm{kg}^{\mathrm{a}}$ & $6.4(6-7)$ & $6.5(6-7.3)$ & $6.3(5.9-6.9)$ & 0.53 \\
\hline Plateau pressure, $\mathrm{cm} \mathrm{H}_{2} \mathrm{O}^{\mathrm{a}}$ & $24(20-26)$ & $20(18-22)$ & $25(23-28)$ & $<0.01$ \\
\hline Driving pressure, $\mathrm{cm} \mathrm{H}_{2} \mathrm{O}^{\mathrm{a}}$ & $11(9-14)$ & $8(8-10)$ & $13(12-15)$ & $<0.01$ \\
\hline Compliance, $\mathrm{mL} / \mathrm{cm} \mathrm{H}_{2} \mathrm{O}^{\mathrm{a}}$ & $35(28.5-46.8)$ & $50(46-55.9)$ & $30(25.1-34.6)$ & $<0.01$ \\
\hline Days on ventilator ${ }^{\mathrm{a}}$ & $12(6-22)$ & $12(6-27)$ & $11(5-17)$ & 0.32 \\
\hline Prone, no. $(\%)^{\mathrm{b}}$ & $38(57.6)$ & $16(66.7)$ & $22(52.4)$ & 0.26 \\
\hline Non-survivors, no. (\%) & $13(19.4)$ & $8(33.3)$ & 5 (11.6) & 0.03 \\
\hline
\end{tabular}

ARDS: acute respiratory distress syndrome

a Values expressed as median (interquartile range)

${ }^{\mathrm{b}}$ Received prone ventilation to manage respiratory failure

${ }^{\mathrm{c}}$ Received neuromuscular blockade agents to manage respiratory failure

\section{Non-respiratory complications}

A large proportion of patients developed organ dysfunction with 55 (53.9\%) diagnosed with acute kidney injury; renal replacement therapy was required in 30 $(29.4 \%)$ patients (Table 1). A total of $23(22.5 \%)$ patients had cardiac complications during the ICU stay, $6(5.8 \%)$ diagnosed with non-ST elevation acute myocardial infarction, 5 (4.9\%) with type 2 myocardial infarction and the remaining $12(11.7 \%)$ with probable myocarditis. Echocardiograms were done for 24 patients with no significant abnormality detected except for right ventricular wall motion abnormalities in 1 patient. There were $12(11.7 \%)$ patients with shock requiring multiple inotropes, while $47(46 \%)$ required short-term inotrope use mainly around the time of intubation. The incidence of confirmed thrombotic events was low; 2 (1.9\%) patients were diagnosed with ischaemic cerebrovascular accidents, $2(1.9 \%)$ with deep venous thrombosis and none with pulmonary embolism, with 10 computed tomography $(\mathrm{CT})$ pulmonary angiograms done to exclude the diagnosis.

\section{Lung compliance}

Lung compliance data were available for 67 patients; $24(35.8 \%)$ were classified as having a high compliance phenotype and $43(64.2 \%)$ as having a low compliance phenotype. Among the total of 102 patients with confirmed COVID-19 who required invasive ventilation in the ICU, 21 were excluded because no lung compliance data was available. Nine patients did not 
meet ARDS criteria post-intubation, and the $\mathrm{PaO}_{2} / \mathrm{FiO}_{2}$ $(\mathrm{PF})$ ratio was not assessed after intubation in 5 patients, who were also excluded from the analysis.

Patients with high compliance were significantly older than those in the lower compliance group (median 67 years [IQR 59-71] vs median 58 years [IQR 51-64]; $P<0.01$ ), but there were no other significant differences with regards to demographics, symptoms, days from the development of clinical symptoms to intubation and laboratory results between the 2 groups (Supplementary Online Table 1).

After intubation, the median PF ratio between the 2 groups were not significantly different (low compliance: 166 [IQR 137-226] vs high compliance: 176 [IQR $138-220] ; P=0.53$ ), but plateau and driving pressures were higher in patients with low compliance (Table 2). Lung compliance data were available on day 7 after intubation for 29 patients, allowing assessment of longitudinal changes. Patients who were classified as having low compliance had no significant change at day 7 (1.8mL/ $\mathrm{cm} \mathrm{H}_{2} \mathrm{O}$ [IQR -4.9 to 3.1$\left.], \mathrm{n}=17\right)$. However, there was a significant reduction for patients initially classified as having high compliance $\left(-10.5 \mathrm{~mL} / \mathrm{cm} \mathrm{H}_{2} \mathrm{O}\right.$, [IQR -4.9 to -18.15 ], $\mathrm{n}=12 ; P=0.01$ ) (Fig. 1).

\section{Outcomes}

There were 87 patients who were extubated and discharged from the ICU, and $15(14.7 \%)$ had a fatal outcome. Nonsurvivors were older (median 70 years, IQR $67-75$ vs median 61 years, IQR 52-66; $P<0.01$ ), stayed on the ventilator longer (26 days, IQR $12-27$ vs 8 days, IQR $5-15 ; P<0.01$ ), stayed in the ICU longer (26 days, IQR $11-30$ vs 11.5 days, IQR $7-17.3 ; P=0.01)$ and a higher proportion had acute kidney injury (15 patients [100\%] vs $40[46 \%] ; P<0.01)$. Non-survivors received high-flow nasal oxygen before intubation ( 8 patients [53.5\%] vs 16 $[18.6 \%] ; P=0.01)$, prone ventilation $(15[100 \%]$ vs 38 $[43.7 \%] ; P<0.01)$, neuromuscular blockers $(15[100 \%]$ vs $55[63.2 \%] ; P=0.01)$, and required dialysis (14 [93.3\%] vs 16 [20.3\%]; $P<0.01$ ) (Table 3 ). Non-survivors also had a significant decrease in compliance $(\mathrm{n}=8,-9.3 \mathrm{~mL} / \mathrm{cm}$ $\mathrm{H}_{2} \mathrm{O}$, IQR -4.5 to -15.4 ) between the day of intubation and day 7 of post-intubation, compared with survivors $(\mathrm{n}=21$, $0.2 \mathrm{~mL} / \mathrm{cm} \mathrm{H}_{2} \mathrm{O}$, IQR 4.7 to $-5.2 ; P=0.04$ ) (Fig. 1).

Mortality was significantly higher in patients who were initially in the higher compliance group compared to the those classified as low compliance $(33.3 \%$ vs $11.6 \% ; P=0.03$ ) (Table 3). Using logistic regression to adjust for age, use of high-flow nasal oxygen and acute kidney injury, the effect on mortality remained significant (odds ratio [OR] 3.5, 95\% confidence interval [CI] $1.1-12 ; P=0.04)$. Within the high compliance group, mortality was higher in the subgroup that switched from having high to low compliance (5/7 patients, 57.1\%) compared with those that did not $(1 / 5,20 \%)$ but this was not statistically significant $(P=0.1)$. Other outcomes were not significant between the groups (Supplementary Online Table 2).

\section{DISCUSSION}

In our prospective study of 102 mechanically ventilated patients with COVID-19, we found that mortality was associated with older age, high-flow nasal cannula (HFNC) use, and development of acute kidney injury requiring dialysis. Among patients with lung compliance results post-intubation, mortality was significantly higher in those initially classified as having high compliance compared with low compliance. Among patients with high compliance initially, mortality was associated with a significant decrease in lung compliance in the first week after intubation.

It has been proposed that COVID-19 patients are more likely to present with an "atypical" form of ARDS characterised by severe hypoxaemia with relatively preserved lung compliance and low elastance, termed the L phenotype. ${ }^{11-13,19,20}$ This is in contrast to the $\mathrm{H}$ phenotype, which describes ARDS with low compliance and high elastance, the phenotype more familiar to intensivists. ${ }^{21}$ Distinguishing the ARDS phenotype is important because the 2 phenotypes are predicted to respond differently to alveolar recruitment strategies and high PEEP. In those with preserved compliance, these interventions risk worsening lung injury through overdistention. ${ }^{13}$

Calfee et al. used latent class analysis to identify 2 ARDS phenotypes based on inflammatory markers. They found that recruitment manoeuvres and PEEP were associated with reduced mortality in patients with a hyperinflammatory profile (termed phenotype 2), whereas these manoeuvres increased mortality in those with a less inflammatory phenotype type $1 .{ }^{14}$ More recently, Constantin et al. have shown that ARDS patients can be broadly classified into focal or non-focal ARDS. They reported mortality improvement in those with non-focal ARDS if lower tidal volumes and higher PEEP were used. In contrast, mortality was lower in those with focal ARDS if higher tidal volumes and lower PEEP were used. Equally important, they found that the misclassification resulted in an increased mortality. ${ }^{22}$ It is possible that the clinical response of patients starting with higher compliance is similar to the less hyperinflammatory phenotype 1 as described by Calfee et al., and focal ARDS described by Constantin et al., whereas patients with lower compliance is similar 


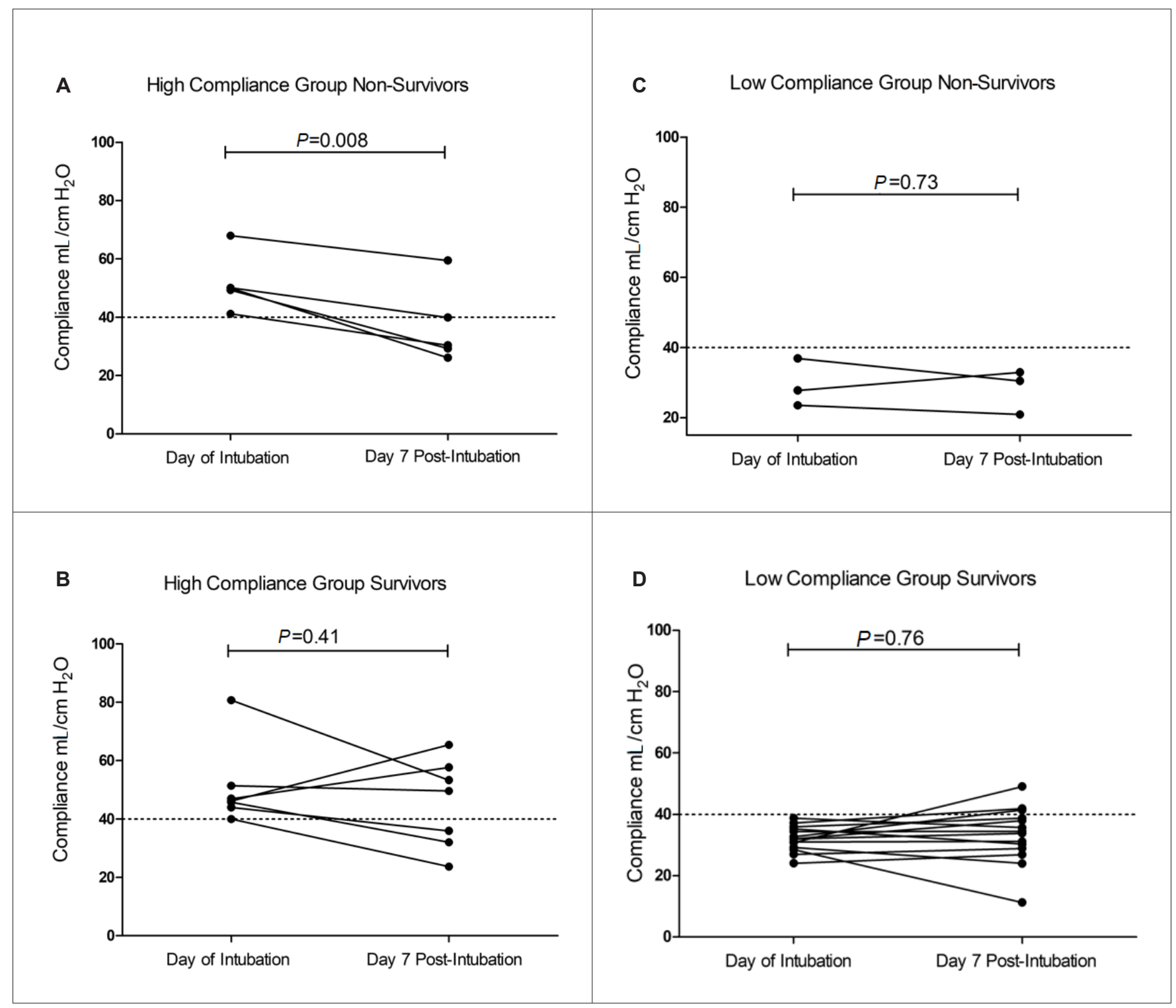

Fig. 1. Lung compliance on the day of intubation and 7 days post-intubation. (A) Patients with high compliance following intubation with a fatal outcome. (B) Patients with high compliance following intubation who survived. (C) Patients with low compliance following intubation with a fatal outcome. (D) Patients with low compliance following intubation who survived.

to inflammatory phenotype 2 and non-focal ARDS. However, C-reactive protein and procalcitonin levels were not significantly different between the groups, although other markers may be more sensitive in the evaluation of inflammation and cytokine release syndrome.

Critically ill COVID-19 patients have an increased risk of cardiac complications and thrombosis. The proportion of patients in the study with cardiac complications appears similar to previous reports. ${ }^{3,23}$ More than half had non-specific elevation in troponin levels with normal electrocardiograms, while the remainder had no evidence of myocardial ischaemia. However, echocardiography done on these patients were normal, except for reduced left ventricular contractility in one patient. Incidences of confirmed ischaemic cerebrovascular accidents, deep venous thrombosis and pulmonary embolism were low in the study.

The mortality rate in the current study was $14.7 \%$, which is lower than that reported among COVID-19 patients with ARDS in Wuhan, where mortality rates ranged from 50 to $65 \% .^{1-3,6}$ Mortality rates have also been reported in the US, with studies from Seattle and New York reporting rates of $50-70 \% 0^{5,9,24}$ Although the mortality rates reported from northern Italy and the UK are lower, they are still close to twice the mortality we observed at $28 \%$ and $37 \%$, respectively. ${ }^{7,8}$ Interestingly, 
Table 3. Oxygen delivery and lung ventilation mechanics for patients who survived and did not survive

\begin{tabular}{|c|c|c|c|c|}
\hline & $\begin{array}{l}\text { Total patients } \\
(\mathrm{N}=102)\end{array}$ & $\begin{array}{l}\text { Survivors } \\
(\mathrm{n}=\mathbf{8 7})\end{array}$ & $\begin{array}{l}\text { Non-survivors } \\
(\mathrm{n}=15)\end{array}$ & $P$ value \\
\hline \multicolumn{5}{|l|}{ Oxygen delivery prior to intubation } \\
\hline Nasal cannula, no. (\%) & $17(16.7)$ & $14(16.3)$ & $3(20)$ & 0.71 \\
\hline Venturi mask, no. (\%) & $34(33.3)$ & $29(33.7)$ & $5(33.3)$ & 1.00 \\
\hline Non-rebreather mask, no. (\%) & $32(31.4)$ & $31(36.0)$ & $1(6.7)$ & 0.03 \\
\hline High-flow nasal cannula, no. (\%) & $24(23.5)$ & $16(18.6)$ & $8(53.3)$ & 0.01 \\
\hline $\mathrm{PaO}_{2} / \mathrm{FiO}_{2}$ prior to intubation ${ }^{\mathrm{a}}$ & $126(87-174)$ & $126(90-176)$ & $122(83-169)$ & 0.83 \\
\hline $\mathrm{PaO}_{2} / \mathrm{FiO}_{2}$ after intubation ${ }^{\mathrm{a}}$ & $183(135-244)$ & $188(140-256)$ & $155(116-189)$ & 0.07 \\
\hline \multicolumn{5}{|l|}{ Lung ventilation mechanics } \\
\hline Positive end expiratory pressure, $\mathrm{cm} \mathrm{H}_{2} \mathrm{O}^{\mathrm{a}}$ & $10(10-12)$ & $10(10-13)$ & $10(8-12)$ & 0.54 \\
\hline Plateau pressure, $\mathrm{cm} \mathrm{H}_{2} \mathrm{O}^{\mathrm{a}}$ & $23(20-26)$ & $24(20-27)$ & $22(19-23)$ & 0.17 \\
\hline Driving pressure, $\mathrm{cm} \mathrm{H}_{2} \mathrm{O}^{\mathrm{a}}$ & $12(9-14)$ & $12(9-15)$ & $10.5(8-13.3)$ & 0.29 \\
\hline Compliance, $\mathrm{mL} / \mathrm{cm} \mathrm{H}_{2} \mathrm{O}^{\mathrm{a}}$ & $35.3(29-47)$ & $34.5(29.1-43.9)$ & $46.8(27.9-53.1)$ & 0.17 \\
\hline Days on ventilator ${ }^{\mathrm{a}}$ & $10(5-17.3)$ & $8(5-15)$ & $26(12-27)$ & $<0.01$ \\
\hline Days in ICU & $13(7-20)$ & $11.5(7-17.3)$ & $26(11-30)$ & 0.01 \\
\hline Prone, no. $(\%)^{\mathrm{b}}$ & $53(52)$ & $38(43.7)$ & $15(100)$ & $<0.01$ \\
\hline Neuromuscular blockade, no. $(\%)^{\mathrm{c}}$ & $70(68.6)$ & $55(63.2)$ & $15(100)$ & 0.01 \\
\hline
\end{tabular}

ICU: intensive care unit

a Values expressed as median (interquartile range)

${ }^{\mathrm{b}}$ Received prone ventilation to manage respiratory failure

${ }^{\mathrm{c}}$ Received neuromuscular blockade agents to manage respiratory failure

a study from Boston, US reported a mortality rate of $16.7 \%$, and also a preponderance of lower over higher compliance. $^{25}$

In Singapore, there has been increased use of HFNC therapy for COVID-19-associated respiratory failure, coupled with awake prone ventilation that has been reported to improve oxygenation. ${ }^{26}$ However, in our study, use of HFNC was associated with increased mortality. Patients may be taking large-volume breaths resulting in patient self-inflicted lung injury, although there was no difference in compliance post-intubation between those who received HFNC and those that did not. A PF ratio of $<200$ has been associated with HFNC failure and the need for invasive ventilation, which may also explain the poorer outcomes in this group. ${ }^{27}$ More studies are needed to understand the optimal usage of HFNC in COVID-19 patients.

Our study had several limitations. Firstly, although ventilator strategies were similar across institutions, the mode of ventilation and management were left to the discretion of the treating physician. Secondly, day 7 compliance data were not available for more than half the patients because most patients were already extubated or undergoing weaning from the ventilator, preventing measurement of plateau pressure. Thirdly, the evolving therapeutic landscape in COVID-19 meant that the majority of critically ill patients received a variety of antiviral therapies, and the effects of these on our ICU outcomes cannot be assessed.

\section{CONCLUSION}

In summary, mortality in mechanically ventilated COVID-19 patients was higher in patients who were older, had acute kidney injury and/or placed on dialysis, and had higher lung compliance at intubation that was associated with decreasing compliance over time.

\section{REFERENCES}

1. Chen N, Zhou M, Dong X, et al. Epidemiological and clinical characteristics of 99 cases of 2019 novel coronavirus pneumonia in Wuhan, China: a descriptive study. Lancet 2020;395:507-13.

2. Huang C, Wang Y, Li X, et al. Clinical features of patients infected with 2019 novel coronavirus in Wuhan, China. Lancet 2020; 395:497-506. 
3. Wang $\mathrm{D}, \mathrm{Hu} \mathrm{B}, \mathrm{Hu} \mathrm{C}$, et al. Clinical Characteristics of 138 Hospitalized Patients With 2019 Novel Coronavirus-Infected Pneumonia in Wuhan, China. JAMA 2020;323:1061-9.

4. Zhu N, Zhang D, Wang W, et al. A Novel Coronavirus from Patients with Pneumonia in China, 2019. N Engl J Med 2020;382:727-33.

5. Richardson S, Hirsch JS, Narasimhan M, et al. Presenting Characteristics, Comorbidities, and Outcomes Among 5700 Patients Hospitalized With COVID-19 in the New York City Area. JAMA 2020;323:2052-9.

6. Yang X, Yu Y, Xu J, et al. Clinical course and outcomes of critically ill patients with SARS-CoV-2 pneumonia in Wuhan, China: a single-centered, retrospective, observational study. Lancet Respir Med 2020;8:475-81.

7. Grasselli G, Zangrillo A, Zanella A, et al. Baseline Characteristics and Outcomes of 1591 Patients Infected with SARS-CoV-2 Admitted to ICUs of the Lombardy Region, Italy. JAMA 2020; 323:1574-81.

8. Docherty AB, Harrison EM, Green CA, et al. Features of 20133 UK patients in hospital with covid-19 using the ISARIC WHO Clinical Characterisation Protocol: prospective observational cohort study. BMJ 2020;369:m1985.

9. Bhatraju PK, Ghassemieh BJ, Nichols M, et al. Covid-19 in Critically Ill Patients in the Seattle Region - Case Series. N Engl J Med 2020;382:2012-22.

10. Bellani G, Laffey JG, Pham T, et al. Epidemiology, Patterns of Care, and Mortality for Patients With Acute Respiratory Distress Syndrome in Intensive Care Units in 50 Countries. JAMA 2016; 315:788-800.

11. Gattinoni L, Coppola S, Cressoni M, et al. COVID-19 Does Not Lead to a "Typical" Acute Respiratory Distress Syndrome. Am J Respir Crit Care Med 2020;201:1299-300

12. Marini JJ, Gattinoni L. Management of COVID-19 Respiratory Distress. JAMA 2020;323:2329-30.

13. Gattinoni L, Chiumello D, Caironi P, et al. COVID-19 pneumonia: different respiratory treatments for different phenotypes? Intensive Care Med 2020;46:1099-102.

14. Calfee CS, Delucchi K, Parsons PE, et al. Subphenotypes in acute respiratory distress syndrome: latent class analysis of data from two randomised controlled trials. Lancet Respir Med 2014;2:611-20.

15. Young BE, Ong SWX, Kalimuddin S, et al. Epidemiologic Features and Clinical Course of Patients Infected With SARS-CoV-2 in Singapore. JAMA 2020;323:1488-94.
16. ARDS Definition Task Force, Ranieri VM, Rubenfeld GD, et al. Acute respiratory distress syndrome: the Berlin Definition. JAMA 2012;307:2526-33.

17. Kidney Disease: Improving Global Outcomes (KDIGO) Acute Kidney Injury Work Group. KDIGO Clinical Practice Guideline for Acute Kidney Injury. Kidney Int Suppl 2012;2:1-138.

18. Bos LDJ, Paulus F, Vlaar APJ, et al. Subphenotyping Acute Respiratory Distress Syndrome in Patients with COVID-19: Consequences for Ventilator Management. Ann Am Thorac Soc 2020;17:1161-3.

19. Grasselli G, Tonetti T, Protti A, et al. Pathophysiology of COVID-19-associated acute respiratory distress syndrome: a multicentre prospective observational study. Lancet Respir Med 2020;8:1201-8.

20. Osuchowski MF, Winkler MS, Skirecki T, et al. The COVID-19 puzzle: deciphering pathophysiology and phenotypes of a new disease entity. Lancet Respir Med 2021;9:622-42.

21. Panwar R, Madotto F, Laffey JG, et al. Compliance Phenotypes in Early Acute Respiratory Distress Syndrome before the COVID-19 Pandemic. Am J Respir Crit Care Med 2020;202:1244-52.

22. Constantin JM, Jabaudon M, Lefrant JY, et al. Personalised mechanical ventilation tailored to lung morphology versus low positive end-expiratory pressure for patients with acute respiratory distress syndrome in France (the LIVE study): a multicentre, singleblind, randomised controlled trial. Lancet Respir Med 2019;7:870-80.

23. Yang X, Yu Y, Xu J, et al. Clinical course and outcomes of critically ill patients with SARS-CoV-2 pneumonia in Wuhan, China: a singlecentered, retrospective, observational study. Lancet Respir Med 2020;8:475-81.

24. Arentz M, Yim E, Klaff L, et al. Characteristics and Outcomes of 21 Critically Ill Patients With COVID-19 in Washington State. JAMA 2020;323:1612-4.

25. Ziehr DR, Alladina J, Petri CR, et al. Respiratory Pathophysiology of Mechanically Ventilated Patients with COVID-19: A Cohort Study. Am J Respir Crit Care Med 2020;201:1560-4.

26. Ng Z, Tay WC, Ho CHB. Awake Prone Positioning for Non-intubated Oxygen Dependent COVID-19 Pneumonia Patients. Eur Respir J 2020;56:2001198.

27. Wang K, Zhao W, Li J, et al. The experience of high-flow nasal cannula in hospitalized patients with 2019 novel coronavirusinfected pneumonia in two hospitals of Chongqing, China. Ann Intensive Care 2020;10:37. 